J. Neurol. Neurosurg. Psychiat., 1958, 21, 167.

\title{
CLINICAL AND ELECTROENCEPHALOGRAPHIC OBSERVATIONS IN ALZHEIMER'S DISEASE
}

\author{
BY \\ F. LETEMENDIA and G. PAMPIGLIONE \\ From the Bethlem Royal and the Maudsley Hospitals and the Institute of Psychiatry, London University
}

Since the beginning of the century a large number of papers have appeared dealing with the pathological and clinical aspects of Alzheimer's disease. Although electroencephalography (E.E.G.) has become a common method of investigation in neurology and psychiatry, very few E.E.G. studies have been reported on histologically proven cases of Alzheimer's disease. In some instances the E.E.G. had been carried out incidentally when the description of the cases was mainly clinical (Stengel, 1943), while in other reports the emphasis was mainly on a therapeutic trial (Sim and Smith, 1955) or on a diagnostic problem (Parr, 1955). Bini (1948), in his monograph on presenile dementias, mentions that the E.E.G. may be normal in some cases or that the alpha rhythm may disappear and be substituted by delta rhythm. The most extensive study appears that of Green, Stevenson, Fonseca, and Wortis (1952) who failed to find any constant difference in the clinical, pneumoencephalographic, and E.E.G. features between five proven cases of Alzheimer's disease and eight of unspecified encephalopathy.

The present study was made in order to assess whether specific E.E.G. features might be recognized in histologically proven cases of Alzheimer's disease and whether E.E.G. investigations might help in the differential diagnosis from other conditions leading to dementia in the presenium. Special consideration was given to the occurrence of seizures and to their relationship to the type and severity of E.E.G. abnormalities.

\section{Material and Methods of Investigation}

Senile plaques and Alzheimer's neurofibrillary changes were found in 17 patients who had had previous clinical and E.E.G. examinations. In 12 of these cases the brain was examined after death and in the remaining five satisfactory information was obtained by cerebral biopsy. In all cases the pathological diagnosis was Alzheimer's disease and the specimens were examined in the Department of Neuropathology of the Institute of Psychiatry.

Sixteen cases were studied clinically at the Bethlem Royal Hospital and the Maudsley Hospital, while one case was seen at St. Ebba's Hospital. The clinical features in our material were fairly uniform. The average age of onset was 52 years, the youngest patient being about 31 , and the oldest 60 . The illness usually began with disturbance of memory and in most cases there was marked apathy. As the disease progressed orientation, speech, written language, and praxis were affected. It was usually at this stage that the clinical diagnosis was formulated. In the final stage a severe dementia and psychomotor restlessness were the dominant features and fits and incontinence were common. Death due to an intercurrent illness occurred, on an average, seven years after the onset of the disease.

The electrical activity of the brain was recorded: (1) In routine resting conditions; (2) after simple stimuli (eye opening or a noise) and during photic stimulation; (3) under the effect of drugs which alter the E.E.G. in a predictable manner in normal subjects.

Either a six- or an eight-channel ink-writing E.E.G. apparatus was used with 20 scalp silver-silver-chloride electrodes. The amplification was of $10 \mathrm{~mm}$. pen deflection for 50 microvolts with a time-constant of 0.3 seconds and a $15 \%$ high frequency cut at $75 \mathrm{c} . / \mathrm{sec}$. The record lasted $30-40$ minutes, including whenever possible three minutes of hyperventilation, and rhythmic

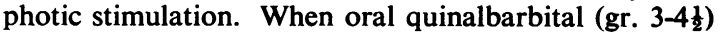
was given this additional part of the record lasted about one hour.

\section{E.E.G. Findings}

An artefact-free record was difficult to obtain as the patient's cooperation was often poor. However, the use of stick-on electrodes proved of great value. In the frontal region, the potential changes due to eye movement were often troublesome but on occasions we were satisfied that a fair amount of the slow activity picked up from the forehead was of cerebral origin.

Fairly uniform features were seen in all the E.E.G.s and no patient had a normal record. Generalized low or medium amplitude (20-100 microvolts) irregular but often rhythmic 4-7 c./sec. activity formed a fairly constant background with superimposed runs of slower waves. Only occasionally did these show a tendency to bilateral synchrony. Often the slowest components $\left(1 \frac{1}{2}-3 \mathrm{c}\right.$./sec. $)$ 


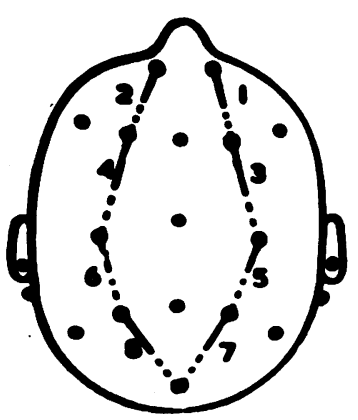

MRS. M.E.G. 16.12.55

50
$55 / 1638$

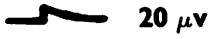

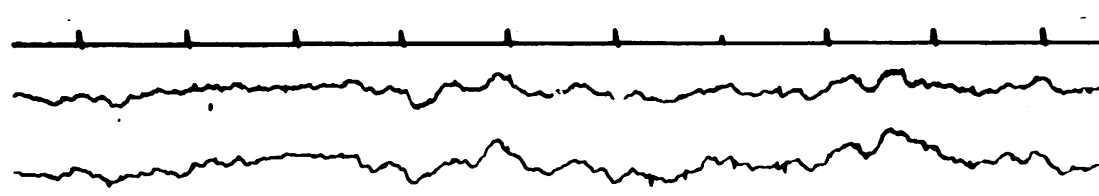
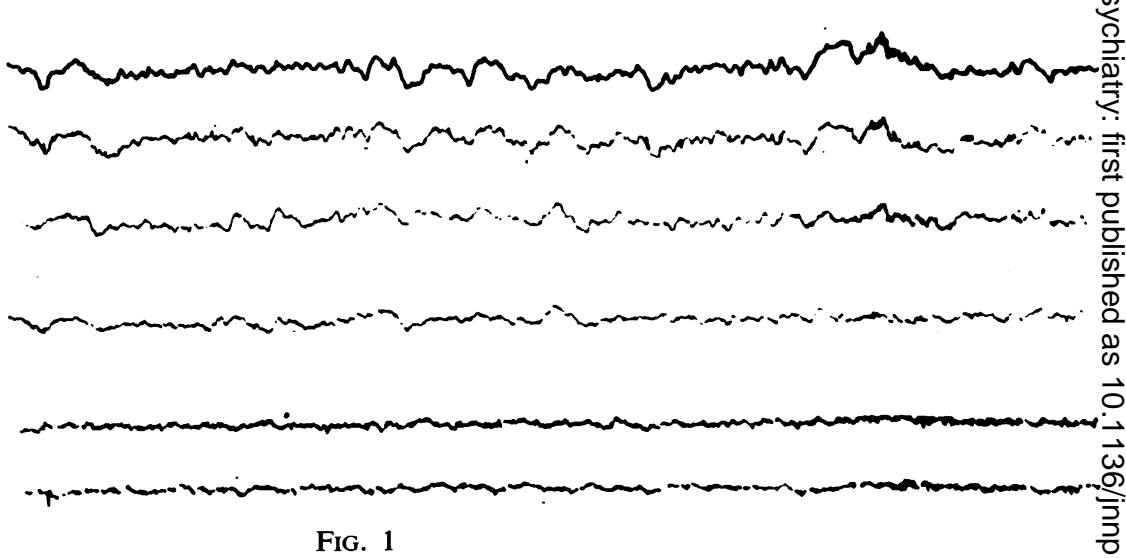

FIG. 1

showed largest amplitude over the anterior part of the head (Fig. 1).

We have classified the severity of the E.E.G. abnormalities in three groups according to the amount of slow activity seen in the first routine resting record of each patient (predominance +++ , fair amount ++ , small amount + ).

In 11 of our cases no alpha rhythms were present in the generalized mixture of slower frequencies. When the alpha rhythms could be recognized these were unstable and scanty, but seemed to be independent of the generalized 4-7 c./sec. activity. Simple stimuli, such as a noise or eye opening, sometimes blocked all activities irrespective of the presence or absence of alpha rhythms.

In Table I some of the E.E.G. features are shown and grouped according to the degree of E.E.G. abnormality in each case. Alpha rhythms were still present in one of the cases with severe E.E.G. abnormality $(+++)$ and in three of those with moderate abnormality $(++)$.

TABLE I

SEVERITY OF E.E.G. ABNORMALITY RELATED TO PRESENCE OR ABSENCE OF CERTAIN E.E.G. FEATURES

\begin{tabular}{|c|c|c|c|c|}
\hline & \multicolumn{3}{|c|}{ Degree of E.E.G. Abnormality } & \multirow{2}{*}{ Totals } \\
\hline & $\begin{array}{l}\text { Severe } \\
+++\end{array}$ & $\begin{array}{c}\text { Moderate } \\
++\end{array}$ & $\begin{array}{c}\text { Mild } \\
+\end{array}$ & \\
\hline $\begin{array}{c}\begin{array}{c}\text { Alpha present } \\
\text { absent } \\
\text { Blocking present } \\
\text { absent }\end{array} \\
\begin{array}{c}\text { Slow present } \\
\text { absent }\end{array} \\
\begin{array}{c}\text { Asymmetries present } \\
\text { absent }\end{array} \\
\begin{array}{c}\text { Discharges present } \\
\text { absent }\end{array}\end{array}$ & $\begin{array}{l}1 \\
4 \\
2 \\
3 \\
5 \\
0 \\
2 \\
3 \\
2 \\
2\end{array}$ & $\begin{array}{r}3 \\
7 \\
7 \\
4 \\
6 \\
10 \\
0 \\
4 \\
6 \\
6 \\
4 \\
6\end{array}$ & $\begin{array}{l}2 \\
0 \\
2 \\
0 \\
2 \\
0 \\
0 \\
2 \\
0 \\
2\end{array}$ & $\begin{array}{r}6 \\
11 \\
8 \\
9 \\
17 \\
0 \\
6 \\
11 \\
6 \\
11\end{array}$ \\
\hline
\end{tabular}

However, after stimuli the activity was blocked in two cases of severe E.E.G. abnormality and in four of those with a moderate abnormality. Ampli tude, or frequency, asymmetries between the् activities of the cerebral hemispheres were notice 2 able in six of the 17 cases.

Transient E.E.G. disturbances in the form of sharp waves, rarely spikes, were seen in six caseso These transient disturbances, lasting 50-100 milli seconds, showed no constant location and some of times had a tendency to bilateral synchrony (Fig. 2). Only three of these six patients developed seizures, two during the six months preceding death. However, seizures were not uncommon and occurred in 11 of our 17 patients, including two with myoclonic jerks and one with only a single convulsion. One patient had had seizures all her life. The severity of the E.E.G. abnormality did not appear to be related to the presence or absence of seizures by the time the first E.E.G.s were obtained: of the four patients who had had seizures before the first E.E.G. study, one showed a severe E.E.G. abnormality, two a moderate, and one a mild E.E.G. abnormality. The rest had either terminal seizures or no seizures at all. activity was noticed, more marked over the anterior part of the hemispheres. However, only five of our patients were able to hyperventilate for three minutes.

Rhythmic photic stimulation could be adequately performed in six cases and in all of them responses to single flashes could be recognized in the occipital region. In contrast to the apparent disorganization
During overbreathing a slight increase in slow 


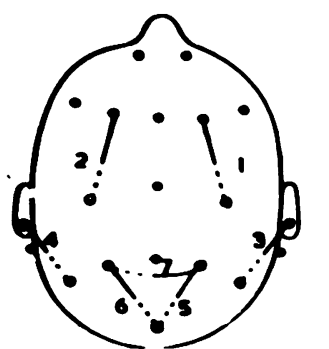

MRS. L.A.H. 64

17.6.53 $\quad 6788$

$\sim 20 \mu v$
Photic Stimulation

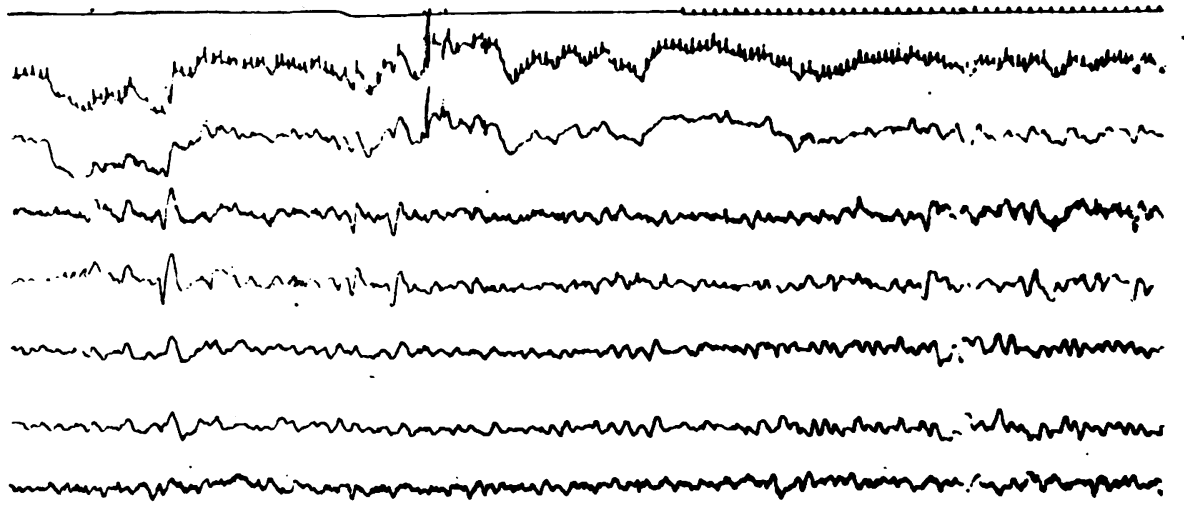

FIG. 2

of background activity, the responses were fairly well preserved and appeared symmetrical over the parieto-occipital regions (Fig. 2). In one of our

patients irregular sharp waves, spikes, and large slow waves were elicited by photic stimulation. This patient never had seizures.

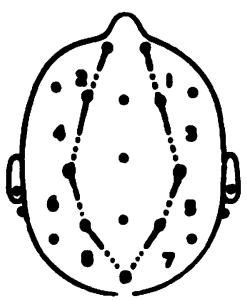

MRS. E.S. 59 $55 / 0059$

18.1 .55
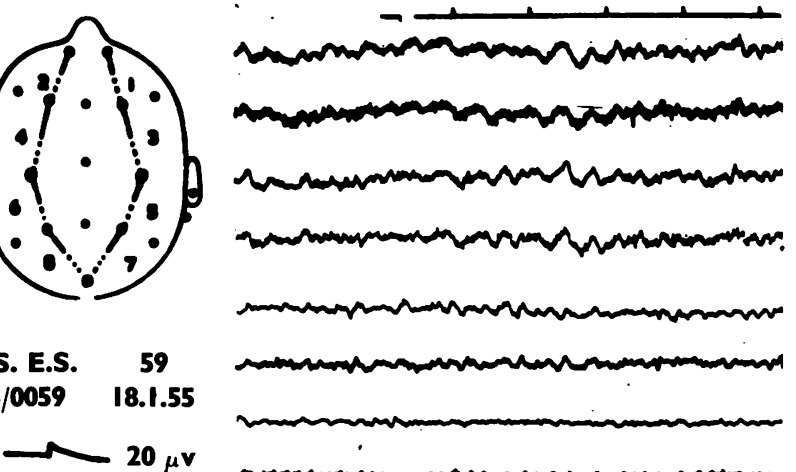

A

(1)

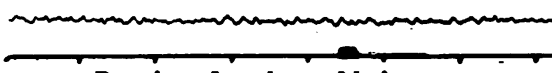

Resting Awake Noise

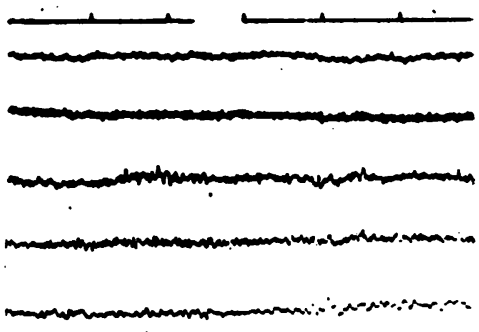

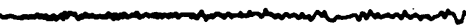

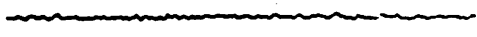

10 mins after Seconal Gr. 3 Awake

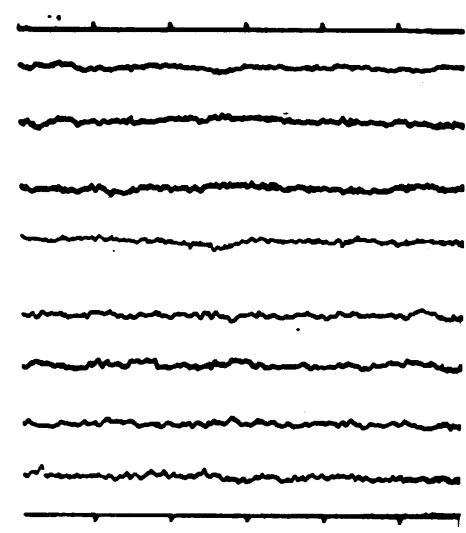

30 mins after Seconal Very Drowsy

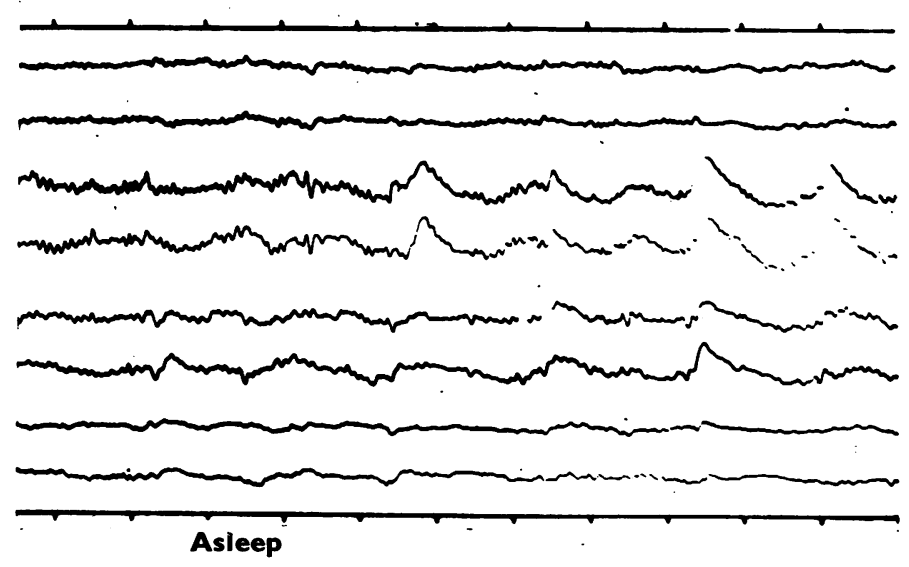

FIG. 3 

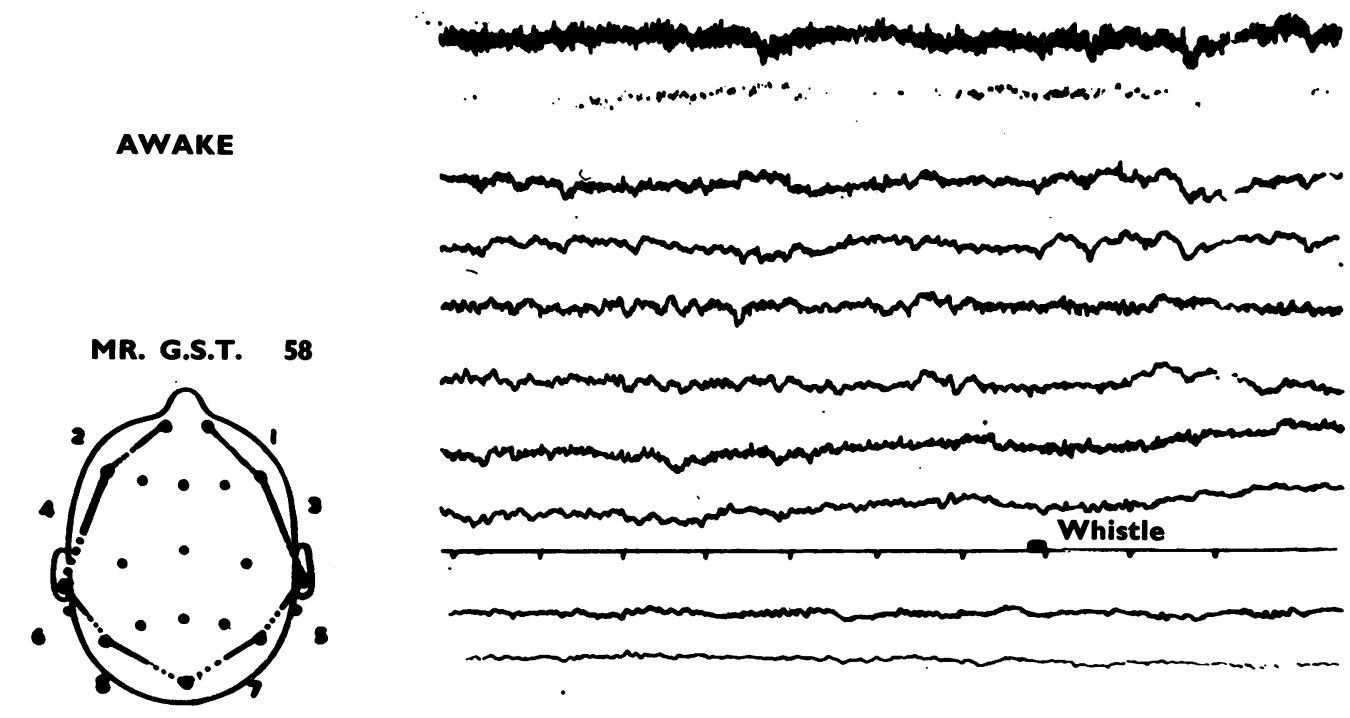

3.2.55

$56 / 0135$
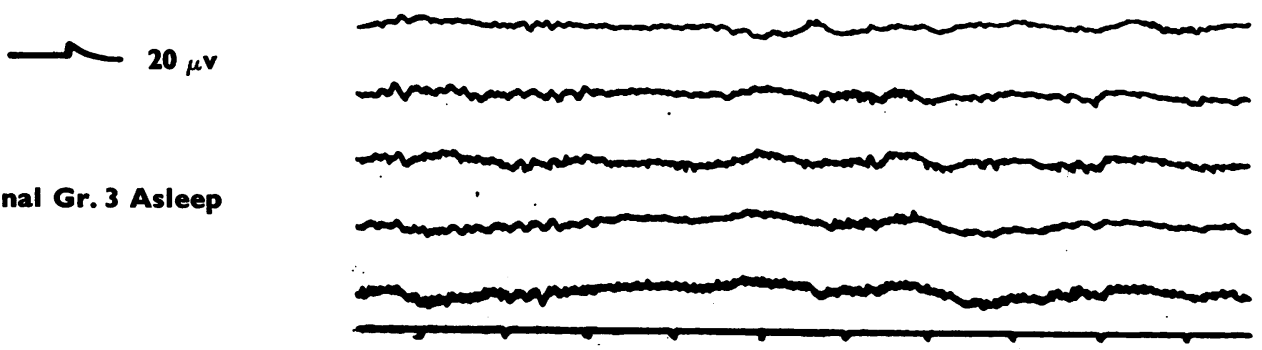

Fig. 4

A relatively quick acting barbiturate (quinal-

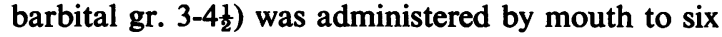
patients. This additional investigation was performed to assess: (1) The distribution of barbiturateinduced fast activity; (2) the E.E.G. changes during drowsiness and sleep; (3) the effects of sensory stimuli during sleep.

In all cases the barbiturate-induced fast activity was scanty and when recognizable was mainly seen near the vertex. It was usually absent from the prefrontal and fronto-temporal regions. However, the generalized slow activity seen in the routine resting E.E.G. appeared to diminish gradually after the administration of quinalbarbital both during drowsiness and early sleep (Figs. 3 and 4). Sleep spindles were recognized in four of the six cases independently of the degree of abnormality in the resting waking record, but were usually of small amplitude over the anterior frontal regions (Fig. 3). Large repetitive slow waves were seen during deeper sleep with a tendency to bilateral synchrony. Sen- sory stimuli (noises, calling the patient by name, touching the patient's hand) appeared to evoke $\mathrm{K}$ complexes less easily than in other patients of similar age group in a comparable state of sleep. Again no constant asymmetries were noticed during sleep between the activities of the two hemispheres even when some asymmetry was present during the waking state.

\section{Discussion}

The present contribution based on 17 histologically proven cases of Alzheimer's disease suggests that the E.E.G. abnormality found in all cases is of an unusual type. The slow activity in the resting records did not appear to be related to the patient's drowsiness as it was increased by overbreathing and on the contrary diminished during induced drowsiness and early sleep. Moreover, the poverty of alpha rhythms with a diffuse predominance of slower activities, the sequence of changes from the resting state to overbreathing, to drowsiness and 
barbiturate-induced sleep, and the poor fast activity response to barbiturate are uncommon in other conditions.

The slow activity in the waking state was generalized, often irregular, though sometimes rhythmic. It was not of the sinusoidal $2-3 \mathrm{c}$. $/ \mathrm{sec}$. kind seen, for example, during overbreathing in young subjects, during hypoglycaemia, during recovery after a major seizure, or as a phénomène a distance in circumscribed cerebral lesions. The amplitude of the slow activity in most records during the waking state was between 50 and 150 microvolts. The uniform distribution of the slow activity over both hemispheres with such an amplitude contrasts with the rather low amplitude slow activity with patchy distribution seen in cerebrovascular disease. In tumours of the corpus callosum the runs of slow activity may appear similar to those of our cases, but usually the alpha rhythms are well preserved in the background. In unilateral intracranial tumours the irregular slow activity is usually fairly well localized.

The poor fast activity response to barbiturates is not related to the age group of the patients tested (sixth decade). In fact, in a group of elderly psychiatric patients, Pampiglione and Post (1955) found that even after 80 years of age the barbiturateinduced fast activity could appear with features closely similar to those found in younger subjects. The scanty fast activity seen in our patients was recorded mainly from electrodes in the para-central region, that is to say, that most other areas of the brain did not modify their activity in a normal way in response to the drug (Pampiglione, 1952, 1954). It is tentatively suggested that the poor barbiturateinduced response in the E.E.G. of our patients might be in keeping with the diffuse cortical lesion characteristic of Alzheimer's disease.

It was considered unprofitable to relate the E.E.G. features to the degree of plaque formation because of the variable time interval between the date at which the E.E.G. studies were performed and the time of death. For the same reason the degree of cerebral atrophy and the main distribution of the plaques were not compared with the E.E.G. findings. It is, in fact, probable that the histological picture varies gradually in each case over months and years and the post-mortem findings may not be a faithful picture of the extent of the pathological process at the time of the E.E.G. studies.

Although cerebral biopsy can provide information about histological changes in the brain soon after the E.E.G. studies, the smallness and localized nature of the specimen permits no generalization about the distribution and severity of the lesions.

A number of patients suffering from dementia in the presenium have been studied at the Bethlem Royal and the Maudsley Hospitals. From this material, in addition to our 17 proven cases, we have collected 19 other cases of the Alzheimer-Pick syndrome in which satisfactory E.E.G. studies were performed. In 15 of these air encephalograms showed some degree of cerebral atrophy. The clinical and E.E.G. features were similar to those of our histologically proven cases (see preliminary communication Letemendia and Pampiglione, 1956) and to three proven cases examined by Dr. D. W. Liddell (personal communication, 1956). In spite of such a similarity we have limited this paper to the histologically verified cases for the following reasons.

In the literature most of the authors do not specify whether their cases were diagnosed only on clinical data and/or pneumoencephalography, or whether histological verification was obtained. In the last few years only Green et al. (1952), Sim and Smith (1955), and Parr (1955) state that a cerebral biopsy was obtained from those of their patients who had E.E.G. studies.

A variety of E.E.G. features have been described in patients suffering from so-called "presenile atrophy ", " demence atrophique", and " presenile dementia " (Mengoli, 1951; Mundy-Castle, Hurst, Beerstecher, and Prinsloo, 1954; Hill, 1948, 1955; Rossini, Reggiani, and Zanocco, 1955). These terms are broad and vague, cannot be taken to define any clinico-pathological entity, and probably cover a variety of pathological conditions. The inclusion of unverified cases in the literature of the E.E.G. changes in Alzheimer's disease may account for this lack of uniformity.

In the 12 brains in our series examined at necropsy the atrophy was usually diffuse. Macroscopic cerebrovascular lesions were seen only in one case according to Dr. J. Brierley who examined the brains of our group of patients. In another case an asymptomatic meningioma, one inch in diameter, was found in the left posterior fossa. The E.E.G.s in these two cases were not substantially different from those of the others, apart from showing a moderate asymmetry between the activities of the two cerebral hernispheres.

The E.E.G. abnormality in the individual case was unrelated to the severity of the dementia or to any particular manifestation including aphasic, agnostic, or apractic disturbances. In our series the incidence of fits was rather higher than that reported in the literature. Rothschild (1934) found seizures in 16 out of 53 cases in his review of the literature, Stengel (1953) noted four patients with fits in his series of nine cases, and Sjögren, Sjögren, and Lindgren (1952) four out of 18. In spite of the high 
incidence of seizures in our group of cases, the type and severity of the E.E.G. abnormalities did not appear to be related to the occurrence (or to the absence) of fits.

It might be possible to study longitudinally by serial E.E.G. a restricted number of patients in order to assess more precisely whether any fluctuations occur in the E.E.G. pattern of an individual patient over a period of years. In some of our cases up to four E.E.G.s were taken over a one-year period without any significant change in the pattern. However, we were unable to obtain systematic serial routine waking E.E.G.s largely because of the patients' poor cooperation. We did not think it profitable to perform serial E.E.G. studies during barbiturate-induced sleep, as the abnormalities in our series of cases appeared to diminish during sleep, even when gross during the waking state.

We may conclude that the E.E.G. abnormalities seen in our group of proven cases of Alzheimer's disease are unusual in other conditions. Careful study of E.E.G.s may help the clinician in the differential diagnosis of presenile dementias, particularly when the possibility either of cerebrovascular disease or of an intracranial tumour has to be considered.

\section{Summary}

Clinical and electroencephalographic studies were made in 17 cases of Alzheimer's disease, later verified histologically (in 12 from necropsy material and in five from cerebral biopsy).

The clinical and E.E.G. features are discussed, including the E.E.G. changes during photic stimulation, after administration of barbiturates, and during sleep.

The common E.E.G. findings were: Absent or scanty alpha rhythms; generalized $2-7 \mathrm{c}$./sec. activity poorly affected by sensory stimuli, slightly increased by overbreathing but clearly diminished during drowsiness; well-preserved responses to photic stimulation; and poor fast activity response to barbiturates. Sleep spindles were recognizable though often of low amplitude; K-complexes were only infrequently evoked by sensory stimuli.

The E.E.G. abnormalities were fairly uniform in all cases without constant relationship to the duration and severity of the clinical picture, the presence or absence of fits, or the patient's age.

It appears that careful E.E.G. investigations may help the clinician in the differential diagnosis of patients presenting with dementia in the presenium.

We are indebted to Professor A. Meyer and Dr. J. Brierley for post-mortem and histological studies; to Mr. P. Schurr for the cerebral biopsies; to the late Dr. Sands and to Dr. Irwin (St. Ebba's Hospital) for access to the notes and E.E.G.s of one patient; to Professor Stengel and Dr. D. Hill for their advice and encouragement; and to Sir Charles Symonds, Dr. G. Russell, and Dr. J. Marshall for their suggestions and criticisms.

\section{REFERENCES}

Bini, L. (1948). Le demenze presenili. Ediz. Italiane, Rome.

Green, M. A., Stevenson, L. D., Fonseca, J. E., and Wortis, S. B. (1952). Dis. nerv. Syst., 13, 303.

Hill, D. (1948). Proc. roy. Soc. Med., 41, 242

(1955). In Recent Advances in Neurology and Psychiatry, $\frac{\overparen{D}}{\mathrm{D}}$ 6th ed., by Brain, Sir Russell and Strauss, E. E. Churchill, $\varrho$ London.

Letemendia, F., and Pampiglione, G. (1956). Electroenceph. clin. Neurophysiol., 8, 345.

Liddell D. W. (1956). Personal communication.

Mengoli, G. (1951). Riv. Neurol., 21, 172. Cited by Rossini et al., Riv. Neurol., 22, 166. (1952)

Munday-Castle, A. C., Hurst, L. A., Beerstecher, D. M., and Prinsloo, T. (1954). Electroenceph. clin. Neurophysiol., 6, 245.

Pampiglione, G. (1952). lbid., 4, 79.

- (1954). lbid., 6, 346.

-, and Post, F. (1955). In Old Age in the Modern World. Report of the Third Congress of the International Association of Gerontology, London, 1954, p. 430 . Livingstone, Edinburgh Gerontology,

Parr, D. (1955). J. ment. Sci., 101, 387.

Rossini, R., Reggiani, R., and Zanocco, G. (1955). Riv. Pat. nerv. ment., 76, 999.

Rothschild, D. (1934). Amer. J. Psychiat., 91, 485.

Sim, M., and Smith, W. T. (1955). J. ment. Sci., 101, 604.

Sjögren, T., Sjögren, H., and Lindgren, A. G. H. (1952). Acta psychiat. neurol. scand., Suppl. 82.

Stengel, E. (1943). J. ment. Sci., 89, 1. 